\title{
Modelos en tensión: las disputas entre el obispo y los curas párrocos en torno a la centralización de la Iglesia católica en la década de 1930 (Tucumán, Argentina)
}

\section{Models in Tension: the Disputes between the Bishop and Parish Priests Regarding the Centralization of the Catholic Church in the 1930s (Tucuman, Argentina)}

\author{
Lucía Santos Lepera \\ Instituto Superior de Estudios Sociales \\ Conicet-Universidad Nacional de Tucumán, Argentina \\ (D) orcid.org/0000-0001-6088-8134 \\ luciasantoslepera@gmail.com
}

Resumen: El objetivo de este artículo es analizar las tensiones que atravesaron la relación entre el obispo, Agustín Barrere, y los curas párrocos de la diócesis de Tucumán en la década de 1930. Con ese fin, indagamos en la reforma del clero que buscó impulsar el nuevo prelado, regida por el ideal de un modelo de sacerdocio basado en la unidad y la obediencia a la jerarquía. Se sostiene la hipótesis de que las políticas obispales encontraron fuertes resistencias entre los curas párrocos, cuyas experiencias al frente de las parroquias de la diócesis modelaron una tradición propia de su papel, opuesta al perfil de cura proyectado por Barrere. En esa dirección, analizamos dos casos de sacerdotes cuya labor pastoral los llevó a un enfrentamiento abierto con la jerarquía, poniendo al descubierto los límites de las políticas obispales.

Palabras clave: Iglesia católica; romanización; obispo; curas párrocos; Tucumán. 
Abstract: This article analyzes the tensions in the relationship between the bishop, Agustín Barrere, and the parish priests of the Tucumán diocese in the 1930s. To this end, we explore the reform of the clergy that sought to promote the new prelate, whose ideal model of priesthood was based on unity and obedience to hierarchy. This supports the hypothesis that the bishop's policies encountered significant resistance from the parish priests, whose experiences with the diocese's parishes shaped a specific tradition for their role, in opposition to the priest profile projected by Barrere. In this regard, we analyze two cases of priests whose pastoral duties led them to an open confrontation with the hierarchy, revealing the limits of the bishop's policies.

Key words: catholic Church; romanization; bishop; parish priests; Tucumán.

Fecha de recepción: 19 de mayo de 2014 Fecha de aceptación: 6 de abril de 2015

T ejos de haber constituido un proceso unívoco y lineal, la romanización Lde la Iglesia católica en América Latina reflejó una dinámica compleja representada por la recepción y adhesión dispar de las iglesias locales a las políticas centralizadoras impulsadas desde el Vaticano. Definido como una tendencia mundial de la Iglesia que condujo a la concentración del poder papal en los terrenos dogmático, doctrinario y disciplinario, el proceso de romanización se manifestó a través de la creación del Colegio Pío Latinoamericano en 1858, la injerencia en las políticas locales mediante el envío de nuncios apostólicos, la celebración del Primer Concilio Plenario de América Latina en 1899 (cuyo principal fin fue uniformar la disciplina eclesiástica) y la sanción del Código de Derecho Canónico en 1917. ${ }^{1}$ La tesis de la romanización adquirió especial relevancia en la historiografía sobre la Iglesia católica al ofrecer un marco interpretativo sobre la centralización de la autoridad papal y sus efectos en las iglesias nacionales desde mediados del siglo xix. ${ }^{2}$

${ }^{1}$ Dentro de la amplia bibliografía que reflexionó sobre esta tendencia de la Iglesia caben destacar las historias generales de Aubert et al. (1977, p. 65-75) y Schatz (1992). Otra dimensión de este proceso en Saranyana (2002, pp. 225-252). Sobre el impacto de estas políticas en la Iglesia argentina véase Di Stefano y Zanatta (2000).

2 En un reciente estado de la cuestión sobre las investigaciones en torno a la Iglesia católica en México y Argentina, Miranda Lida (2007) ha dado cuenta del modo en que la tesis de la romanización -junto a la de la secularización-modelaron un marco interpretativo desde el cual se abordó el estudio de la Iglesia entre fines del siglo xix y principios del xx. En

\section{()(1) $\$$}


No obstante los numerosos avances en esa dirección, aún resta profundizar enfoques que ponderen el impacto, los alcances y las resistencias que las políticas vaticanas generaron en las estructuras eclesiásticas locales. Es decir, resulta necesario ahondar las reflexiones críticas en torno a la idea de una romanización progresiva e inexorable, desde una perspectiva que problematice y matice ese proceso.

A tono con este proceso general, durante las primeras décadas del siglo xx la Iglesia argentina se fortaleció institucionalmente, ganó presencia en el espacio público y, en consecuencia, consolidó su influencia social y política. ${ }^{3}$ Los alcances de ese desarrollo se evidenciaron hacia los años treinta, periodo de importantes conquistas para la Iglesia. En ese marco, los logros institucionales tales como el nacimiento de la Acción Católica, la creación de diez nuevas diócesis y la organización del Congreso Eucarístico Internacional estuvieron acompañados por un clima cultural y social de "renacimiento católico". La Iglesia parecía, de ese modo, crecer a "la sombra de la romanización" y adquirir un perfil fiel al proyecto papal de centralizar y jerarquizar la institución eclesiástica. Tal cuadro de situación llevó a algunos autores a caracterizar a la Iglesia argentina como "una de las que más internalizó" ese proceso (Di Stefano y Zanatta, 2000, pp. 332-336).

Este artículo avanza en la contraparte del proyecto centralizador de la Iglesia, es decir, en las resistencias, tensiones y conflictos que atravesaron el proceso de crecimiento y consolidación institucional. Con este fin, retoma las reflexiones críticas sobre la producción bibliográfica en torno a la historia de la Iglesia católica en los años treinta. Estas sentaron las bases para repensar la imagen de una institución eclesiástica que, a partir de su creciente fortaleza, unidad y disciplina, había conseguido conquistar posiciones sociales, políticas e ideológicas, y con ello convertir al catolicismo en un pilar de la identidad nacional. ${ }^{4}$

consecuencia, se proyectó una historia signada por los ciclos de "derrota" frente a las reformas liberales, de deseos de "revancha" y de "triunfo" hacia la década de 1930.

${ }^{3}$ Se trató de un proceso de cambios ampliamente abordado por la historiografía. Desde distintas perspectivas, los estudios sobre la Iglesia de los años treinta dieron cuenta de las políticas desplegadas por las cúpulas eclesiásticas, de los vínculos estrechos que estas construyeron con las Fuerzas Armadas y el Estado y de las transformaciones ideológicas por las que atravesó el catolicismo en esa década (Bianchi, 1997, 2002; Di Stefano y Zanatta, 2000; Ghio, 2007; Mallimacci, 1988, y Zanatta, 1996).

${ }^{4}$ Trabajos recientes llamaron la atención sobre la necesidad de revisar estas premisas. Brindaron nuevos aportes tendentes a complejizar la idea de "renacimiento católico" y a atenuar el carácter rupturista con el que se había concebido la década de los treinta en la historia

\section{()(1) $\$$}


A través del análisis de la diócesis de Tucumán, el estudio busca dar cuenta del proyecto de Iglesia plasmado por el obispo Agustín Barrere quien, desde su asunción en 1930, impulsó un conjunto de medidas con el objeto de ordenar el funcionamiento de la institución y robustecer la autoridad eclesiástica. Sin embargo, el proceso de afirmación del poder obispal no fue sencillo ni estuvo exento de tensiones, especialmente frente a un clero diocesano cuya tradición de autonomía fue difícil soslayar. En ese marco, nos interesa indagar en la reforma eclesiástica dirigida al cuerpo de sacerdotes de la diócesis, centrado en modelar un perfil de cura acorde a las exigencias de disciplina y unidad que emanaban de la codificación eclesiástica. Se sostiene la hipótesis de que las políticas obispales de centralización encontraron fuertes resistencias entre los curas párrocos, cuyas experiencias al frente de las parroquias de la diócesis modelaron una tradición opuesta al perfil proyectado por Barrere, centrado en la obediencia a la jerarquía.

Con el fin de estudiar más detenidamente las tensiones que atravesaron las relaciones del obispo y los curas párrocos, analizamos dos casos de sacerdotes cuya labor pastoral los llevó a un enfrentamiento abierto con la jerarquía, poniendo al descubierto los límites de las políticas obispales y desnudando las contradicciones implícitas al proyecto de Barrere. Este modo de analizar el problema busca revisar la noción de una Iglesia en la que el principio de autoridad que guía las relaciones de obispos y sacerdotes supone la obediencia indiscutible. En ese sentido, la reflexión en torno al modo en que los curas párrocos concibieron su papel nos lleva a reparar en las tensiones que atravesaron su relación con el obispo y, en definitiva, en las pugnas por los modelos de sacerdocio. ${ }^{5}$ Pero también nos remite al problema de los alcances y límites de la reforma del clero, una arista del proceso de romanización de la Iglesia católica que implicó tensiones y enfrentamientos entre los actores eclesiásticos.

de la Iglesia (Lida, 2009). En esta línea, véanse también otros trabajos de la autora (Lida, 2006, 2010) y de Diego Mauro (2009 y 2010).

${ }^{5}$ En este enfoque, retomamos una fructífera línea de investigación desarrollada para el periodo tardocolonial y comienzos del siglo xix que indagó en torno al papel y perfiles de los párrocos, su autonomía y condicionamientos, y los cambios en el ejercicio del ministerio parroquial (Ayrolo, 2006; Barral, 2007). Sobre la renovación de los estudios sobre el clero en la historiografía argentina (Di Stefano, 2008).

\section{(이요}




\section{LAS DIFICULTADES DE LA CONSTRUCCIÓN DE LA AUTORIDAD OBISPAL}

En 1930, Agustín Barrere se convirtió en el tercer obispo de la diócesis de Tucumán y ejerció su gobierno a lo largo de 22 años, hasta su fallecimiento en 1952. La diócesis, creada en los estertores del siglo XIX, había terminado de conformar sus límites poco antes, cuando las provincias de Santiago del Estero y Catamarca se separaron (1907-1910) y su territorio coincidió con el de la provincia de Tucumán. ${ }^{6}$ De ese modo, Barrere asumía al frente de una diócesis relativamente nueva cuya creación respondía a un proceso más amplio de descentralización de la estructura territorial de la Iglesia argentina y de modernización de la administración eclesiástica (Di Stefano y Zanatta, 2000).

La carrera del nuevo prelado se adecuó a la trayectoria que en general siguió la jerarquía católica, en la que predominaban las carreras burócratas en las estructuras episcopales o las carreras docentes en los seminarios, donde las funciones parroquiales no formaban parte (Bianchi, 1997, p. 30). Si bien nació en Buenos Aires, durante su infancia su familia se trasladó a Francia, país en el que Barrere estudió e ingresó a la Congregación de Padres Lourdistas. Posteriormente fue enviado a la Universidad Gregoriana en Roma donde se graduó con el doble título de doctor en Filosofía y Teología. En efecto, aquellos seminaristas que mostraban destacadas aptitudes eran enviados a Roma con el objeto de formar funcionarios eclesiásticos dentro de la disciplina vaticana y del más estricto tomismo, garantizando así la adhesión a la autoridad papal. Barrere, "destacándose entre los mejores", transitó este camino. ${ }^{7}$ Una vez ordenado sacerdote en 1891, fue destinado a Argentina donde tras una larga trayectoria como sacerdote, en la que se desempeñó como docente y director del Seminario Conciliar de Tucumán, Barrere se consagró obispo a los 65 años de edad. Ciertamente, su formación romana, su subordinación a la au-

${ }^{6}$ De ese modo, los límites de la diócesis coincidieron con los límites políticos de la provincia, cuyos $22836 \mathrm{~km}^{2}$ y sus 216000 habitantes la convirtieron en una de las más densamente pobladas $\left(9.33\right.$ habitantes por $\mathrm{km}^{2}$ ), cifra que la ubicó por encima del resto de los distritos. Datos extraídos del II Censo nacional de 1895 (Bravo, 2008, p. 27). Véase mapa 1.

${ }^{7}$ Bodas de oro sacerdotales. Boletín Oficial de la Diócesis de Tucumán (en adelante BODT), 13 de abril de 1941, p. 133. Otras biografías: Ecos de la consagración de mons. Barrere. BODT, 17 de agosto de 1930, p. 68; S. E. Rdma. Mons. Agustín Barrere. BODT, 30 de septiembre de 1947, p. 1. Véase también mons. Agustín Barrere. FARO. Boletín parroquial del Sagrado Corazón de Jesús, 25 de agosto de 1968, p. 2; Falleció anoche el obispo Barrere. La Gaceta, 29 de febrero de 1952, p. 1.

\section{()(1) $\$$}


Mapa 1. Ubicación de la diócesis de Tucumán en Argentina (división política)

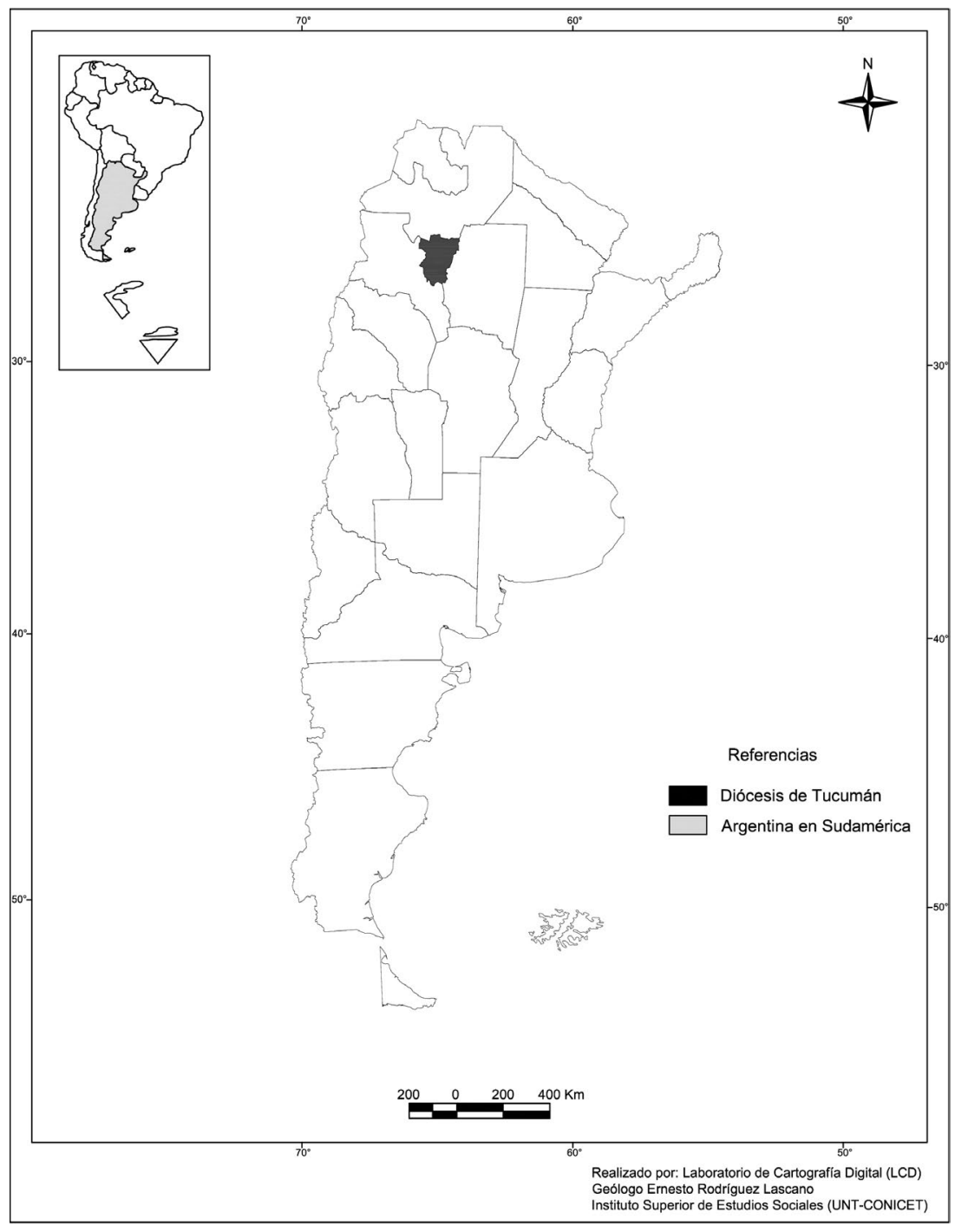

\section{(ㄷ)(1) $(2)$}


toridad vaticana y su compromiso con el proceso de romanización influyeron en el perfil de su gestión pastoral al frente de la diócesis.

Desde que Agustín Barrere asumió como obispo se produjeron profundas transformaciones en la institución eclesiástica tucumana. El alto perfil que sostuvo en su gestión renovó un estilo de ejercer el poder eclesiástico caracterizado por la incorporación de rasgos monárquicos y por la centralidad de su figura en el despliegue de las ceremonias religiosas, destinadas a reafirmar su autoridad especialmente hacia adentro de la institución. ${ }^{8}$ Según lo recordaba José I. Bassols, prosecretario del obispado, la imagen pública de Barrere era "la de un príncipe de la Iglesia" que se distinguía por "su solemnidad, su porte y su boato", lo cual contrastaba "con la imagen humilde y austera de su antecesor, Mons. Bernabe Piedrabuena". ${ }^{9}$ En efecto, el obispado de Bernabe Piedrabuena (1911-1928) tuvo características muy distintas y su figura, estrechamente vinculada a las elites locales, representó el perfil de prelado que la reforma eclesiástica impulsada desde el Vaticano buscó reemplazar. ${ }^{10}$

El ambicioso proyecto desplegado por el nuevo obispo tenía como horizonte el ideal de una institución eclesiástica fuerte, monolítica y disciplinada. Sintetizado en la imagen de una Iglesia centralizada bajo la autoridad del obispo, el modelo que Barrere buscó imponer encontró respuestas diversas entre los actores eclesiásticos. En ese sentido, las políticas dirigidas al laicado católico fueron, tal vez, las que rindieron mayores frutos y redundaron a favor del fortalecimiento de la autoridad obispal. ${ }^{11}$

En efecto, durante esos años se conformó la Acción Católica Tucumana (АСТ) como una asociación cuyo objetivo fue reunir las actividades de los laicos en una entidad única, alineada bajo las directivas de la jerarquía. Esta

${ }^{8}$ Sobre esta reformulación del poder episcopal, que entre 1935 y 1957 fue "revestido de rasgos monárquicos" véase Bianchi (1997, p. 33).

9 Testimonio del pbro. José I. Bassols publicado en el diario La Gaceta a raíz de la muerte del obispo: Bassols J. I. Falleció anoche el obispo Barrere, La Gaceta, 29 de febrero de 1952, p. 1.

${ }_{10}$ Piedrabuena pertenecía a una familia de la elite política tucumana. Su abuelo, Bernabé Piedrabuena, había sido gobernador de Tucumán entre 1838 y 1840, y su padre fue, asimismo, militar y político. En efecto, la reforma eclesiástica impulsada desde Roma buscó terminar con las autonomías y vínculos locales que mantenían ciertos obispos con las elites provinciales. En Argentina esta se plasmó en 1934 cuando el Episcopado renovó sus miembros a raíz de la designación de nuevos obispos y del pedido de renuncia a los que no respondían a las condiciones requeridas desde el Vaticano (Bianchi, 1997; Zanatta, 1996, pp. 128-131).

${ }^{11}$ Cabe aclarar que esta alusión a las políticas dirigidas al laicado no implica el desconocimiento de las tensiones que atravesaron el proceso de conformación de la Acción Católica Tucumana, aspecto que hemos abordado en otros trabajos (Santos Lepera, 2009 y 2010).

\section{(이요}


fue el pilar sobre el que se asentó la Iglesia para ganar las calles a partir de las movilizaciones católicas y, de este modo, proyectar una imagen de orden y solidez en la institución eclesiástica. Las grandes movilizaciones católicas que caracterizaron los años treinta fueron decisivas para forjar el ideal de fortaleza a partir del cual la Iglesia se concibió a sí misma y se proyectó en la sociedad. Tales movilizaciones, con sus columnas perfectamente ordenadas, presididas por el obispo diocesano junto a las autoridades políticas y militares, fueron una puesta en escena de la centralidad que pretendía la Iglesia en la sociedad tucumana y permitieron visualizar cada vez más su presencia pública. Las multitudes que congregó el I Congreso Eucarístico Diocesano en 1933, la consagración de la diócesis al corazón de María en 1944 y el I Congreso Mariano Diocesano en 1945, fueron un reflejo de ese nuevo catolicismo organizado pero también dieron cuenta de las transformaciones de la década. ${ }^{12}$

El proyecto de Barrere también contempló al clero diocesano. No obstante, estos últimos revelaron ser un actor más disruptivo que el laicado y, en gran medida, se mostraron refractarios a las reformas que el prelado buscó imponer. Al definir el obispado como una "forma de gobierno aristocrática", Barrere manifestó que sólo el obispo tenía "por derecho propio y con toda plenitud, la potestad de enseñar", considerando a los sacerdotes como "auxiliares y delegados" suyos. ${ }^{13}$ Desde esa perspectiva, el proyecto que tenía para el clero secular tuvo como eje promover entre estos la obediencia y la disciplina. El primer paso en esa dirección fue la promulgación del II Sínodo Diocesano, cuya reglamentación ofreció señales claras desde el punto de vista doctrinario y eclesiológico. ${ }^{14}$

La promulgación del Segundo Sínodo Diocesano en 1931 buscó principalmente ordenar el funcionamiento de la diócesis y contribuir a la efectiva disciplina del clero. Este reglamentó la forma de organización de la institución, los deberes referidos a la curia eclesiástica, a los clérigos seculares y regulares, y se refirió a las costumbres de los fieles católicos. En palabras

12 En los últimos años la historiografía avanzó en el estudio de las movilizaciones católicas durante el periodo de entreguerras. Desde la perspectiva de una historia social del catolicismo, estos trabajos tendieron a revisar el abordaje de esas movilizaciones como "supuestas exteriorizaciones de la alianza entre la cruz y la espada", señalando la importancia de las transformaciones urbanas y las características propias de una sociedad de masas para explicar las "movilizaciones católicas" (Lida y Mauro, 2009; Mauro, 2010, p. 15).

${ }_{13}$ Barrere A. La misión sacerdotal. BODT, 10 de enero de 1943, p. 2.

${ }^{14}$ La necesidad de adaptar la legislación eclesiástica a las disposiciones del Código de Derecho Canónico promulgado por el papa Benedicto XV en 1917, llevó a Barrere a realizar la convocatoria de un nuevo Sínodo (Obispado de Tucumán, 1931).

\section{(ㄷ)(1) $(3$}


del obispo, la nueva legislación no era "simplemente un acontecimiento trascendental en los anales de la diócesis, sino un poderoso fermento de renovación espiritual para todos; para los pastores antes que para la grey". ${ }^{15}$ De este modo, uno de los principales objetivos fue fortalecer las jerarquías dentro de la organización institucional de la Iglesia tucumana, destacando las prerrogativas de la figura del obispo y los deberes del clero diocesano.

Si la puesta en marcha del Sínodo fue una muestra de las ansias de modelar una Iglesia ordenada y obediente, su implementación reflejó la distancia entre el orden proyectado por este y la dinámica de funcionamiento de la institución. Según lo expresó en su primera visita ad limina, el obispo se encontró con un cuerpo de sacerdotes cuyas prácticas -entre las que describió la asistencia a espectáculos públicos y cafés, la convivencia con parientes en la casa parroquial, el escaso respeto a las formas de la liturgia y la ortodoxia doctrinal, y la acumulación de deudas con la "fábrica" de sus iglesias $-{ }^{16}$ no "correspondían" a la conducta del clero. ${ }^{17}$ Barrere apuntaba a modelar un clero "profesional", instruido y disciplinado, cuyas actitudes y comportamientos fuesen una pauta de distanciamiento del mundo seglar. ${ }^{18}$ Sin embargo, la disciplina del clero implicó una negociación constante por parte del obispo, quien alternó los llamados de atención sobre las conductas "inapropiadas" con las sanciones eclesiásticas, a las cuales recurrió sólo excepcionalmente.

Tal fue el caso de José Ferrán, cura párroco de la iglesia Sagrado Corazón, quien en 1937 fue objeto de una "amonestación severa" a raíz de su discurso agraviante contra el obispo en el marco de un banquete de homenaje al prelado de Cartagena. En la fundamentación del apercibimiento que impartió al párroco, Barrere aludió especialmente a la mala conducta del sacerdote

${ }^{15}$ Discurso de cierre del Segundo Sínodo Diocesano de Tucumán celebrado en la iglesia catedral del 14 al 18 de abril de 1931 (Obispado de Tucumán, 1931, p. 242).

${ }^{16}$ La fábrica era el fondo que solía tener una iglesia para realizar reparos edilicios o costear los gastos del culto. Los ingresos y egresos debían figurar en el "Libro de fábrica" que cada iglesia conservaba y debían ser siempre autorizados por el obispo.

${ }_{17}$ Visita ad limina 1934. Fondo Documentos Eclesiásticos. Caja visitas ad limina s/n. Archivo del Arzobispado de Tucumán (en adelante AAT), San Miguel de Tucumán, Argentina.

${ }^{18}$ En esa dirección, los obispados anteriores habían buscado, aunque de forma esporádica e incontinua, implementar algunos aspectos de la reforma del clero, pasos que Barrere intentó retomar y profundizar. Bajo el obispado de Padilla y Bárcena, Barrere había sido llamado a colaborar en la confección del I Sínodo Diocesano (1905), el cual sentó las bases organizativas sobre las que funcionó la diócesis por casi 30 años. Durante el obispado de Piedrabuena se comenzaron a implementar las "conferencias del clero" y se redactaron manuales para párrocos.

\section{()(1) $\$$}


quien, "contrariamente a lo dispuesto en el Sínodo Diocesano", frecuentaba el café Japonés, un centro de reunión y sociabilidad de la capital donde acudían miembros de la elite política y social. ${ }^{19}$ No obstante, las tensiones de fondo con el obispo parecían tener su antecedente en la oposición férrea que ejerció Ferrán al proyecto del prelado de trasladar la sede de la parroquia Sagrado Corazón (que funcionaba en la catedral a falta de sede propia) a un barrio de menores recursos. ${ }^{20}$ De forma similar, entre 1935 y 1938 Barrere sostuvo enfrentamientos con los miembros del clero diocesano Agustín Arrázola, Máximo Bruser, Domingo Vargas Cubillo, Felín Linares Alurralde y Pedro Ripoll. ${ }^{21}$ Estos también se desenvolvieron en torno a problemas por la "conducta" del clero, que involucraron desde desobediencias a directivas obispales a la inobservancia de la liturgia en la celebración de misas o de procedimientos dispuestos en el Sínodo respecto a la inscripción de partidas en los libros de bautismos parroquiales. ${ }^{22} \mathrm{~A}$ diferencia de lo ocurrido con Ferrán, estos casos sólo generaron reiteradas "advertencias" por parte de la jerarquía, sin derivar en sanciones eclesiásticas.

La creación de La Semana Católica (boletín oficial de la diócesis que reprodujo las palabras y directivas de la jerarquía local), también reveló los límites que encontró el proyecto del obispo en su instrumentación. Los ejemplares del boletín debían ser adquiridos por todas las parroquias con el fin de homogeneizar las prédicas de los curas párrocos y difundir las actividades de la diócesis. Sin embargo, su creación originó múltiples tensiones. En

${ }^{19}$ Comunicado del obispado a José Ferrán. 10 de septiembre de 1937. Fondo Clero Diocesano. Caja legajos s/n (José Ferrán). AAт, San Miguel de Tucumán, Argentina.

${ }^{20}$ Carta al "Venerable Cuerpo de Consultores Diocesanos" de Barrere. 11 de abril de 1932. Fondo Clero Diocesano. Caja legajos s/n (José Ferrán). AAT, San Miguel de Tucumán, Argentina. Barrere criticaba el "poco celo evangelizador" de Ferrán quien se encontraba en "situación cómoda y bien rentada en la catedral", causando "daños espirituales" a los feligreses desde hacía diez años.

${ }^{21}$ Fondo Clero Diocesano. Caja legajos s/n (Agustín Arrázola, Máximo Bruser, Domingo Vargas Cubillo, Felín Linares Alurralde, Pedro Ripoll). AAт, San Miguel de Tucumán, Argentina. Sobre los llamados de atención y amonestaciones eclesiásticas, Visita ad limina 1934. Fondo Documentos Eclesiásticos. Caja visitas ad limina s/n. A AT, San Miguel de Tucumán, Argentina. De la revisión de los legajos personales del clero diocesano de la diócesis, se desprende que Barrere sostuvo, a lo largo de la década de los treinta, conflictos con al menos catorce sacerdotes.

${ }^{22} \mathrm{Si}$ bien es una variable que no analizamos en este estudio, cabe resaltar que en todos los casos se trataba de sacerdotes extranjeros que habían llegado a la diócesis en las primeras décadas del siglo xx. Excepto el cura Bruser (nacido en Gerlingen, Westfalien, Alemania) todos eran españoles. Sobre el papel del clero extranjero, los imaginarios en torno a este y los conflictos con la jerarquía por cuestiones de disciplina, véase Gallardo (2010).

\section{(ㄷ)(1) $(3$}


primer lugar, no todos los párrocos compraron el hebdomadario dado que lo consideraron de tinte "exclusivista" porque no publicaba las noticias de las comunidades parroquiales locales y porque, teniendo en cuenta su bajo número de lectores, su costo era muy alto para ser afrontado por la fábrica de las iglesias. ${ }^{23}$ Así lo reveló el caso de Juan Avellá, cura párroco de Lules entre 1935 y 1949, quien elevó reiteradas quejas al obispo en respuesta a la insistencia de este en que se pusiera al día con la compra de la publicación. ${ }^{24}$ Desde el obispado reconocieron las dificultades de muchos párrocos que se rehusaban a comprar La Semana Católica, por lo que decidieron suspender los envíos como una forma de "ejercer presión" ${ }^{25}$ A pesar de la insistencia de Barrere, tal estrategia no surtió los efectos esperados y los curas siguieron acumulando deudas, lo que generó finalmente que la publicación diocesana disminuyera su frecuencia por falta de suscriptores. Aunque el boletín puso en evidencia las dificultades que debió enfrentar el obispo para construir su autoridad, su publicación fue un paso importante en la difusión de las directivas y orientaciones ideológicas de la jerarquía católica con el fin de homogeneizar los procedimientos de una Iglesia que necesitaba progresar en su articulación institucional.

Junto con el propósito de disciplinar al clero diocesano, Barrere procuró aumentar su número a través de distintas estrategias, aspecto central para promover el crecimiento institucional de la diócesis y proyectar la tan ansiada catolización de la sociedad..$^{26}$ Se ensayaron distintas vías para promover la carrera eclesiástica como la creación del secretariado de las Vocaciones Eclesiásticas, la organización de "cruzadas vocacionales", la difusión

${ }^{23}$ Desde un principio, el Boletín definió a sus destinatarios como un "público restringido, capacitado y culto", es decir, "de elite". Se trataba según sus editores de una "prensa de ideas y de sentimientos elevados" dedicado a quienes los compartían. Nuestro Programa. BODT, 4 de agosto de 1929, pp. 2 y 3.

${ }^{24}$ Carta a Juan Avellá de Barrere, 2 de marzo de 1938; Carta a Agustín Barrere de Avellá, 14 de marzo de 1938. Fondo Clero Diocesano. Caja Legajos s/n (Juan Avellá). A AT, San Miguel de Tucumán, Argentina.

${ }^{25}$ En el Boletín Diocesano se publicaba información fundamental para los párrocos como los días que debían asistir a los ejercicios espirituales, los decretos y comunicados del obispo, los datos relativos a traslados y permisos especiales otorgados a los curas, etcétera.

${ }^{26}$ Para el desarrollo de la red parroquial de la diócesis era indispensable el crecimiento del número de sacerdotes que pudiesen asumir la dirección de esas nuevas parroquias. El problema de la "escasez de clero" atravesó todo el periodo y siempre fue objeto de queja de la jerarquía eclesiástica. Como indica Susana Bianchi, si bien durante la década de 1930 crecieron las vocaciones eclesiásticas, frente al modelo español (23000 sacerdotes diocesanos para 1950) "la Iglesia argentina era un desierto" (Bianchi, 1998, p. 2).

\section{()(1) $\$$}


del "Apostolado de la Oración" y se organizaron las Jornadas de la Vocación Eclesiástica y el día del Seminario, con el fin de recaudar fondos para donar becas a los aspirantes al sacerdocio. Hacia principios de la década de los cincuenta, los frutos de tales políticas se volvieron visibles: el cuerpo del clero diocesano que hacia 1931 estaba conformado por 43 sacerdotes, aumentó su número a 59 miembros. Las vocaciones eclesiásticas también crecieron durante aquellos años: si en 1934 la diócesis contaba con 49 seminaristas, hacia 1942 Barrere podía jactarse de haber duplicado su número a $106{ }^{27}$

Desde la perspectiva del obispo, el aumento de la cantidad de curas y recursos resultaba indispensable para proyectar, simultáneamente, la extensión de la red parroquial. La diócesis de Tucumán englobaba a un conjunto heterogéneo de parroquias muy dispares entre sí en lo relativo a su extensión, cantidad de población, perfil socioeconómico, etc. ${ }^{28} \mathrm{Al}$ asumir Barrere como obispo, existían 19 parroquias, de las cuales sólo cuatro estaban ubicadas en la capital (dos de ellas a cargo del clero regular). Debido a las políticas institucionales desplegadas durante su gestión, las parroquias aumentaron su número a 30 (se crearon once parroquias, cuatro en la ciudad capital y siete en el interior de la provincia). Con el fin de conseguir recursos económicos, el prelado se valió de la colaboración de algunos industriales azucareros, responsabilizándolos de la congrua, es decir, del sustento de las nuevas parroquias y de sus curas (Santos Lepera, 2012). En líneas generales, se trató de una política exitosa ya que el número de parroquias erigidas durante su gestión representó 37\% del total que conformaban la diócesis.

En este proceso resultó fundamental la creación del Seminario Regional de Catamarca (1932). Su fundación respondía a la estrategia de las autoridades eclesiásticas del noroeste argentino (Salta, Tucumán, Santiago del Estero y Catamarca) tendente a favorecer la formación de un clero local empapado de las necesidades pastorales de la región. Según los obispos, era necesario que "el clero se forme en el ambiente en el que va a actuar y aprenda, desde el seminario, a ceñirse a las exigencias de una vida modesta que,

27 Guías eclesiásticas de 1938, 1946 y 1952. A AT, San Miguel de Tucumán, Argentina. Véase también, Visita ad limina 1934, Fondo Documentos Eclesiásticos. Caja visitas ad limina s/n. AAT, San Miguel de Tucumán, Argentina.

28 El entramado parroquial de la diócesis se había ido desarrollando desde fines del siglo XIX al calor del "despegue" de la agroindustria azucarera. Las parroquias se concentraron principalmente en el área del piedemonte tucumano, al suroeste de la capital, donde predominaba la población dedicada a la elaboración de azúcar.

\section{(ㄷ)(1) $(3$}


en su ministerio, tendrá que llevar". ${ }^{29}$ Hasta ese momento, los aspirantes al sacerdocio se trasladaban a los seminarios de las provincias de Córdoba, Buenos Aires y Santa Fe para seguir sus estudios. El hecho de enviar a los seminaristas a centros de formación distantes de su lugar de origen despertaba entre los obispos muchas reservas: "en el contacto con alumnos de diócesis más afortunadas y de costumbres menos sencillas haría que, a su regreso, se encontraren como extraños en casa propia". ${ }^{30}$ De este modo, durante su gestión Barrere hizo explícita la intención de promover un "clero nativo", es decir incentivar la formación sacerdotal de jóvenes oriundos de la diócesis tucumana. $^{31}$

Los obispos decidieron que el seminario Mayor de Catamarca fuese regido por la Sociedad del Verbo Divino, una congregación religiosa de sacerdotes alemanes con amplia experiencia en este campo. ${ }^{32}$ Aparte de la formación que impartían en los ciclos de filosofía y teología -tal como disponía el Código de Derecho Canónico-, estos pusieron énfasis en la formación científica de sus alumnos, en la promoción de actividades culturales (en especial las academias literarias y el cultivo de la música de tradición alemana y del folclore local) y en la práctica del deporte. Así recordaba Honorio Soria su paso por el seminario: "nos formaban muy bien. Los seminaristas iban a Catamarca con muy distinta base, la enseñanza era bastante pobre en el seminario menor, pero en el mayor los alemanes nos exigían mucho [...] había 40 alumnos, no más. Aprendíamos heráldica, historia y medicina, aparte de filosofía y teología." ${ }^{33}$ Ciertamente, a partir de la fundación del nuevo seminario regional la formación del clero tucumano tendió a homogeneizarse:

${ }^{29}$ Carta pastoral sobre la fundación del Seminario Mayor Regional del Norte. BODT, 27 de marzo de 1932, p. 704.

${ }^{30}$ Carta pastoral sobre la fundación del Seminario Mayor Regional del Norte. BODT, 27 de marzo de 1932, p. 704.

${ }^{31}$ Visitas ad limina 1944 y 1949. Fondo Documentos Eclesiásticos. Caja visitas ad limina s/n, AAt, San Miguel de Tucumán, Argentina.

${ }^{32}$ El Seminario Regional funcionó en la sede del antiguo Seminario Conciliar de Catamarca (creado en 1891). Este último había sido regido primero por los padres lourdistas y después por el clero diocesano. El nuevo seminario funcionó con el presupuesto destinado por el Ministerio de Culto de la Nación a través del pago de sueldos a los profesores y de las becas que otorgaba. Asimismo, el aporte de las diócesis del noroeste era central: debían cubrir los gastos de la pensión de sus seminaristas.

${ }^{33}$ Recuerdos de Segundo Honorio Soria sobre su paso por el seminario de Catamarca. Entrevista realizada por Lucía Santos Lepera, el 24 de noviembre de 2005, San Miguel de Tucumán.

\section{(ㄷ)(1) $(3$}


quienes aspiraban a hacer la carrera sacerdotal iniciaban sus estudios en el seminario Menor de Tucumán y los finalizaban en el de Catamarca.

En suma, el proyecto de Barrere buscó, por un lado, promover la disciplina de los sacerdotes en su encuadramiento bajo la autoridad obispal y, por otro, afirmar en la diócesis a un clero oriundo de Tucumán, consustanciado con los problemas locales de la comunidad. Las especificaciones del Sínodo diocesano y la formación impartida en los seminarios apuntaban a que los aspirantes internalizaran un complejo papel: el de ser "profesionales" de lo sagrado a la vez que desempeñaban sus funciones insertos en la vida cotidiana de las poblaciones parroquiales. No obstante, como veremos, el modelo de cura que buscó imponer Barrere, basado en las nociones de disciplina y obediencia a la figura inapelable del obispo, tropezó con las prácticas de los curas párrocos. Desde la perspectiva de estos, la situación era mucho más complicada. Si bien los sacerdotes que ejercían el ministerio parroquial le debían obediencia al obispo -la autoridad máxima de la diócesis- necesitaban equilibrar su gestión entre las directivas del obispado y las reglas que les imponía la propia dinámica de funcionamiento de la parroquia. Los párrocos se encontraban en el difícil lugar intermedio entre la jerarquía y los fieles.

\section{LOS CURAS PÁRROCOS DE TRANCAS Y SIMOCA: FUNCIONES Y TENSIONES CON LA JERARQUÍA}

Así como el proyecto de Barrere abrió la posibilidad de que los sacerdotes siguiesen el camino propuesto y respondiesen al modelo de cura proyectado por el prelado, existieron otros perfiles de párrocos con los que surgieron tensiones, cuya labor reflejaba una concepción de sus funciones muy distinta. La función bifronte de los sacerdotes llevó a estos a desenvolverse bajo la disyuntiva entre la obediencia a la jerarquía y el acercamiento a la comunidad de fieles. Se trató de una tensión entre dos fidelidades. De ese modo, en su vinculación directa y cotidiana con la población parroquial a través de un lenguaje mundano y más plebeyo, los curas operaron en espacios muy distintos a los de la jerarquía eclesiástica. Así lo reflejaron las trayectorias de los curas párrocos de Trancas (Pablo Rodríguez Melero) y Simoca (Alberto Soldati) que, de forma parecida, pusieron en cuestión el proyecto del obispo y desnudaron las contradicciones inherentes al mismo. Como veremos, ambas trayectorias representaron dos casos extremos, ya que sus enfrentamientos

\section{()(1) $(9$}


con el obispo derivaron en la expulsión de la diócesis de Rodriguez Melero y en el abandono forzado de las funciones como párroco de Soldati.

Pablo Rodríguez Melero constituyó el perfil de cura al que estaban dirigidas las políticas desplegadas por el obispo Agustín Barrere con el objeto de reformar y disciplinar al clero. El sacerdote español regía desde 1928 una de las parroquias más extensas y alejadas de la capital, lugar donde residía la jerarquía eclesiástica. ${ }^{34}$ En parte, tal distancia incidió en su desempeño como un párroco que gozaba de amplias cuotas de libertad en su jurisdicción respecto de las directivas obispales. Sin embargo, fue la concepción sobre su labor como sacerdote -divergente al modelo que buscaba imponer Barrere-la fuente de conflictos que llevó a Rodríguez Melero a ser expulsado de la diócesis.

Desde que Barrere asumió como obispo había sostenido una relación tirante con el párroco de Trancas a quien, en reiteradas ocasiones, le advirtió sobre su comportamiento "indebido". Desde la perspectiva obispal, Rodríguez Melero no cumplía con sus deberes pastorales, se inmiscuía en los problemas mundanos y se "extralimitaba" de sus funciones. Entre 1931 y 1935, el cura fue apercibido por mantener vínculos epistolares con una mujer del pueblo, lo cual era considerado una conducta inmoral, por frecuentar una fonda diariamente para almorzar y cenar, por residir en una pensión en lugar de habitar la casa parroquial y por no promover la conformación de las ramas de Acción Católica. ${ }^{35}$

Las tensiones acumuladas estallaron el 28 de octubre de 1935, cuando Rodríguez Melero recibió un comunicado del obispado donde se le solici-

${ }^{34}$ Fondo Clero Diocesano. Caja Legajos s/n (Pablo Rodríguez Melero). A AT, San Miguel de Tucumán, Argentina. La parroquia se ubicaba en el departamento de Trancas, caracterizado por su gran extensión y su escasa densidad demográfica $\left(2914 \mathrm{~km}^{2}\right.$ y 3.4 habitantes por $\mathrm{km}^{2}$ ). Se trataba de un distrito que carecía de centros urbanos (la población era 100\% rural) y no poseía ingenios azucareros. En efecto, la principal actividad económica de la provincia era la producción azucarera, cuyos establecimientos industriales estaban situados en el centro-sur del territorio provincial, alrededor de los cuales se concentraban también los asentamientos de población. En Trancas predominaba, por el contrario, la producción agrícola-ganadera.

${ }^{35}$ El Sínodo hacía referencia explícitamente a la obligación que tenían los párrocos de residir en la casa parroquial y no ausentarse sin la debida autorización del obispo diocesano. En el capítulo v del Sínodo titulado "De los Párrocos", el artículo in hacía referencia a sus "derechos y obligaciones". Asimismo se dedicó un punto a regular las "costumbres sociales" de los curas párrocos (Obispado de Tucumán, 1931). En general, las disposiciones sobre las conductas de los párrocos fueron reforzadas con decretos del obispo donde especificaba las prohibiciones de andar en bicicleta, concurrir a espectáculos públicos, etc. Fondo Documentos Eclesiásticos. Caja Decretos del obispado (1930-1952). AAT, San Miguel de Tucumán, Argentina.

\section{()(1) $\$$}


taba su renuncia como párroco y se sugería su traslado a otra diócesis. Las causas aducidas se centraban en su "desobediencia", sus "ausencias" de la parroquia sin autorización del obispo, sus "contravenciones a las prescripciones canónicas" y, principalmente, su participación en la cooperativa agrícola que nucleaba a los colonos de Trancas en cuya administración el cura se había "inmiscuido". ${ }^{36}$ El papel protagónico que tuvo Rodríguez Melero en la conformación de la cooperativa y la organización de los colonos con el fin de reclamar la propiedad de la tierra, comportamiento juzgado como "indebido" por la jerarquía, fue la causa que terminó de incidir en el obispo para decretar su expulsión.

En efecto, el sacerdote se había comprometido en la organización de una cooperativa agrícola de campesinos a través de la cual impulsó dos proyectos: la rebaja de las rentas "exorbitantes" que cobraban los terratenientes y el inicio de los trámites correspondientes para conseguir que el Banco Hipotecario Nacional vendiera a los colonos las propiedades que poseía en la localidad de Benjamín Paz. Desde la perspectiva del cura, "el haber sido el promotor de las compras de tierras por los colonos" hizo que la gran mayoría de los campesinos de la zona se acercaran a la Iglesia y a la religión católica. ${ }^{37}$ Como consecuencia, Rodríguez Melero se vio envuelto en un enfrentamiento abierto con los latifundistas a raíz de su defensa de los agricultores y de sus críticas a los "abusos" que aquellos cometían. Según explicó, gracias a su trabajo en la cooperativa logró que los colonos "tengan con que vivir, sin necesidad de estar sometidos a los latifundistas ni tener que estar continuamente adulando al patrón para que los deje trabajar tranquilos en sus tierras". ${ }^{38}$

A lo largo de los años que se desempeñó como párroco, en los que se empapó de los problemas y las demandas de los colonos, Rodríguez Melero elaboró una visión de la cuestión social muy distinta a la mirada que el obispo reproducía en cartas pastorales y comunicados. Desde la perspectiva obispal, los conflictos en el mundo laboral debían encontrar una solución cristiana en la Doctrina Social de la Iglesia, entendida como la "concilia-

${ }^{36}$ Comunicado a Rodríguez Melero del Obispado. 28 de octubre de 1935. Fondo Clero Diocesano. Caja legajos s/n (Pablo Rodríguez Melero). AAT, San Miguel de Tucumán, Argentina.

${ }^{37}$ Carta a Barrere de Rodríguez Melero. 6 de noviembre de 1935. Fondo Clero Diocesano. Caja legajos s/n (Pablo Rodríguez Melero). AAt, San Miguel de Tucumán, Argentina.

${ }_{38}$ Carta a Barrere de Rodríguez Melero. 6 de noviembre de 1935. Fondo Clero Diocesano. Caja legajos s/n (Pablo Rodríguez Melero). AAt, San Miguel de Tucumán, Argentina.

\section{()(1) $(3$}


ción del capital y el trabajo". Su visión conservadora del orden social llevó al prelado a vincularse con los sectores patronales, a quienes interpeló para que asumiesen un papel activo azuzando el miedo del avance de las ideas de izquierda y del desorden social. Según ese esquema, el obrero y su familia mejorarían su situación gracias a la "buena voluntad" de los patrones. ${ }^{39}$ Por el contrario, el párroco de Trancas consideraba necesaria la acción directa de la Iglesia en el terreno social, proceso que implicaba identificarse con los sectores más desfavorecidos. En suma, en el trasfondo del altercado entre el obispo y el cura de Trancas estuvo también en disputa la concepción de la Doctrina Social de la Iglesia. En respuesta a las sanciones del obispo, Rodríguez Melero afirmaba:

Pero aun en el supuesto de que esos individuos, los latifundistas, salieran perjudicados ¿no es preferible el bien de 300 o 400 familias al de una sola por muy aristocrática y distinguida que sea, o mejor dicho, que ella se juzgue? A la luz de la Doctrina Social de la Iglesia y de los principios de la justicia y de la caridad cristiana, no cabía duda alguna en la elección, y todo espíritu recto se inclinará siempre a favor de las 300 o 400 familias beneficiadas, prescindiendo de la una. ${ }^{40}$

Frente a tal desafío, Barrere sostuvo las sanciones recordándole que como sacerdote debía "promover la justicia social, sin provocar reacciones que deban evitarse, bregando por el triunfo de los humildes en la paz de Cristo, por tanto, en la cristiana colaboración del capital y el trabajo". ${ }^{41}$ Según el obispo, la vía para mejorar la situación de los colonos era el "trabajo y el ahorro". Aunque no lo hacía explícito, al referirse a las "reacciones" evitables, indudablemente Barrere aludía a las respuestas de los latifundistas quienes, a raíz de su enfrentamiento con el cura, iniciaron una campaña de difamación del sacerdote y solicitaron reiteradas veces su traslado a otra parroquia. Como era de esperar, Rodríguez Melero acusó al obispo por su actitud de connivencia

39 Barrere A. Carta pastoral del Excmo. Sr. Obispo Diocesano. BODT, 3 de agosto de 1930, p. 5. Véase también Barrere A. Algo sobre la cuestión social. BODT, 21 de junio de 1931, p. 949.

${ }^{40}$ Carta a Barrere de Rodríguez Melero. 6 de noviembre de 1935. Fondo Clero Diocesano. Caja legajos s/n (Pablo Rodríguez Melero). AAt, San Miguel de Tucumán, Argentina.

${ }^{41}$ Carta a Rodríguez Melero de Barrere. 21 de noviembre de 1935. Fondo Clero Diocesano. Caja legajos s/n (Pablo Rodríguez Melero). AAt, San Miguel de Tucumán, Argentina.

\section{()(1) $\$$}


con los sectores patronales en vez de defender su labor como párroco, considerándose una víctima de "los personajes con dinero e influencias". ${ }^{2}$

No obstante las explicaciones esbozadas por el cura y las cartas enviadas por vecinos de la localidad solicitando al obispo que revirtiese su decisión de expulsar al párroco, Barrere sostuvo su postura. A juzgar por el apoyo que recibió de un sector de la población, el párroco de Trancas había conseguido establecer vínculos estrechos con la feligresía y se había erigido en un referente de la localidad, a quien, en especial los colonos, respetaban y valoraban. Ciertamente, cuando Barrere logró que Rodríguez Melero abandonase la localidad de Trancas, un sector de los vecinos se organizó en defensa del párroco y reclamó su regreso. ${ }^{43}$

El modo en que el cura de Trancas concibió su función, modelada en su experiencia al frente de la parroquia, y la autonomía que expresó respecto del obispo, representaban una constante en el accionar de los párrocos, es decir, estaban lejos de constituir una novedad de ese periodo. Lo que sí se había modificado era la política obispal frente a los gestos de desobediencia a la autoridad jerárquica. Barrere buscó controlar más de cerca a los curas párrocos a través de distintas estrategias con el objetivo de infundir los sentidos de unidad y observancia a las directivas obispales. Tal como lo refleja la historia de Rodríguez Melero, se trató de un proceso que no estuvo exento de conflictos y enfrentamientos con los párrocos, cuya posición de fuerza resultaba difícil de modificar.

A diferencia de la trayectoria de Rodríguez Melero, la carrera eclesiástica del presbítero Alberto Soldati respondía a las expectativas del obispo Barrere. A los quince años de edad ingresó al seminario menor de la diócesis donde obtuvo una beca de estudios ya que sus padres no podían afrontar los gastos. Debido a su buen desempeño y a sus aptitudes para convertirse en sacerdote fue enviado al colegio Pío Latinoamericano en Roma y una vez recibido volvió a la diócesis de Tucumán donde se incardinó. ${ }^{44}$ No sólo su formación romana coincidió con el modelo de sacerdocio al que aspiraba el

${ }^{42}$ Carta a Barrere de Rodríguez Melero. 26 de noviembre de 1935. Fondo Clero Diocesano. Caja legajos s/n (Pablo Rodríguez Melero). AAT, San Miguel de Tucumán, Argentina.

${ }^{43}$ Carta del Pbro. Emigdio Courel a Barrere. 31 de marzo de 1936. Fondo Parroquias de la diócesis. Carpeta parroquia de Trancas. AAT, San Miguel de Tucumán, Argentina. En la misma Courel señalaba el malestar entre la población por la expulsión del párroco y describió la organización de los vecinos en "comisiones" para reclamar frente al obispo de la diócesis.

${ }^{44}$ Fondo Clero Diocesano. Caja legajos s/n (Alberto Soldati). A AT, San Miguel de Tucumán, Argentina.

\section{()(1) $\$$}


obispo, sino también su origen: Soldati era tucumano, aspecto que contribuía a robustecer las filas de un clero nativo y que cuadraba con el proyecto del flamante prelado.

En efecto, Soldati había nacido y crecido en el pueblo de Simoca, en el seno de una familia de "cañeros". La presencia de los cañeros era uno de los rasgos que distinguían a la agroindustria azucarera tucumana: se trataba del sector compuesto por campesinos propietarios o arrendatarios de extensiones variables de tierra que se dedicaban al cultivo de la caña de azúcar para luego venderla a los ingenios. ${ }^{45}$ Los problemas recurrentes por el precio de la materia prima y la persistente crisis de superproducción que caracterizó a la agroindustria desde los años veinte signaron la persistente puja de intereses entre los cañeros y los industriales, configurando un escenario altamente conflictivo (Bravo y Gutiérrez, 2009). Junto al departamento de Monteros, Simoca era una jurisdicción donde prevalecía el cultivo de la caña y se concentraban los pequeños y medianos productores. Como veremos, embebido de una tradición familiar de pequeños propietarios cañeros, Soldati pronto se vería involucrado en la defensa de los intereses de los agricultores de la zona, en disputa constante con los ingenios.

Alberto Soldati quedó a cargo de la parroquia de Simoca en 1937 cuando el cura titular de la misma, Andrés Chionetti, solicitó a Barrere que lo nombrase como sucesor dada la grave enfermedad que padecía y que le impedía seguir ejerciendo el ministerio pastoral. ${ }^{46}$ De ese modo, volvió a su pueblo natal con la función de vicario cooperador. Sin embargo, en poco tiempo el cura se vio tironeado entre la observancia de las reglas de la Iglesia y su identificación con la causa cañera. Su participación a fines de los años treinta en los mítines organizados por la Unión Agraria Provincial y su compromiso con las agremiaciones de cañeros le valieron numerosas advertencias del obispo y amonestaciones eclesiásticas. A pesar de las sanciones que le impartieron, el cura Soldati siguió comprometido en la defensa de los cañeros. En 1939 fue uno de los principales oradores, en calidad de "miembro" de la seccional de

${ }^{45}$ Para un análisis exhaustivo sobre los orígenes de este sector y su composición interna, Bravo (2008).

${ }^{46}$ Carta a Barrere de Chionetti. 15 de febrero de 1937. Fondo Parroquias. Carpeta de parroquia de Simoca. Archivo de la Diócesis de Concepción (en adelante ADC), Concepción, Tucumán, Argentina.

\section{()(1) $\$$}


agricultores de Simoca, en el acto organizado en Monteros bajo el patrocinio del Centro Cañero de Tucumán y de la Unión Agraria provincial. ${ }^{47}$

A diferencia de Barrere, que señaló la participación del cura en el movimiento cañero como un "obstáculo" en el ejercicio de su "apostolado sacerdotal", Soldati consideró su adhesión a la causa de los agricultores como "justa y razonable" ${ }^{48}$ Aún más, el vicario cooperador no sólo desafiaba el poder de los industriales, sino también el del gobierno. En 1938, junto con el párroco de Concepción, celebraron una misa en conmemoración de los cañeros reprimidos por la policía en Gastona en 1932. Según el fiscal eclesiástico de la diócesis, César Padilla, se trataba de una "conmemoración en carácter de protesta contra la actitud del gobierno de entonces y en contra de la policía". ${ }^{9}$

Las sanciones impartidas por el obispo se basaban en el capítulo del Sínodo Diocesano dedicado a la conducta del clero donde se prohibía terminantemente la participación en la política. Los sacerdotes se veían obligados a "mantenerse fuera y por encima de todos los partidos, condición imprescindible para el éxito de su ministerio", y debían mantener una relación de "paz y armonía" con las autoridades civiles, siendo "condescendientes en todo lo que no afecte a las leyes de la Iglesia y el decoro sacerdotal" (Obispado de Tucumán, 1931, p. 66). No obstante, el oficio de misas que se vinculaban a algún "pedido político" resultaba una práctica extendida entre los curas párrocos. Pero mientras estas celebraciones tendían a conservar la paz y la armonía y no implicaban desafíos a las autoridades políticas o patronales, el obispo no las reprendía. Por el contrario, cuando los curas se involucraban en la defensa y la reivindicación de algún sector que implicase el cuestionamiento al statu quo, entonces se activaban los mecanismos de disciplinamiento como las sanciones eclesiásticas.

Finalmente, cansado de las presiones y los llamados de atención de Barrere, pero sobre todo de su imposibilidad de acceder a las parroquias subvencionadas por los ingenios dada su condición de hijo de cañeros, Soldati decidió postularse para ser capellán del Ejército y de ese modo asegurarse el sustento. Evidentemente, las perspectivas de Soldati en la diócesis de Tucu-

${ }^{47}$ Una concentración de cañeros hubo ayer en Tucumán. La Nación, 29 de abril de 1939, Buenos Aires, Argentina.

${ }^{48}$ Carta a Barrere de Soldati. 5 de abril de 1942. Fondo Clero Diocesano. Caja legajos s/n (Alberto Soldati). AAт, San Miguel de Tucumán, Argentina.

${ }^{49}$ Carta del secretario del obispado al párroco interino de Concepción. 14 de junio de 1938; Carta al vicario cooperador de Simoca. 14 de junio de 1938. Fondo Parroquias. Carpeta de parroquia de Concepción. ADC, Concepción, Tucumán, Argentina.

\section{()(1) $\$$}


mán no eran muy promisorias. En las iglesias subvencionadas por las fábricas azucareras nunca sería bienvenido, en las zonas ajenas al cultivo de la caña viviría una existencia pobre, casi como un "castigo eclesiástico", y en los pueblos donde el movimiento cañero era importante, como en Simoca, su papel demandaba un compromiso político con la defensa de los agricultores. ${ }^{50}$ Durante la gestión de Barrere, quien puso especial énfasis en controlar cada vez más los comportamientos que vincularon al clero con aspectos "políticos", era muy difícil que un sacerdote como Soldati pudiese desempeñarse sin problemas en la diócesis.

De ese modo, el itinerario del joven cura tucumano demostró los límites de la estrategia del obispo Barrere, cuyas expectativas terminaron naufragando en la imposibilidad de neutralizar las tradiciones familiares y culturales de los sacerdotes locales. Si Barrere esperaba que los párrocos de la diócesis actuaran de acuerdo con las disposiciones del Sínodo diocesano, lo que en términos generales significaba ser respetuosos de las autoridades establecidas, no "extralimitarse" en las funciones del ministerio parroquial $y$, sobre todo, no involucrarse en actividades mundanas (Obispado de Tucumán, 1931, p. 34), el caso de Soldati vino a reflejar que las estrategias desplegadas por el obispo podían generar como resultado un perfil de cura totalmente opuesto a lo proyectado. ${ }^{51}$ En ese caso, las tradiciones familiares y culturales, imbuidas en el hogar y en la vida de los sacerdotes, podían llegar a trascender las actitudes doctrinales aprendidas en el seminario.

\section{CONSIDERACIONES FINALES}

Desde su asunción en la diócesis de Tucumán en 1930, las políticas desplegadas por el obispo Agustín Barrere buscaron dotar a la institución eclesiástica de un mayor sentido de orden y homogeneidad con el fin de profundizar su influencia en la sociedad. La trayectoria previa del prelado, su formación

${ }^{50}$ Carta a Barrere de Soldati. 5 de abril de 1942. Fondo Clero Diocesano. Caja legajos s/n (Alberto Soldati). AAt, San Miguel de Tucumán, Argentina. Asimismo, el padre del joven sacerdote le envió una carta a Barrere preocupado por el futuro de su hijo: Carta a Barrere de Enrique Soldati. 5 de septiembre de 1941. Fondo Clero Diocesano. Caja legajos s/n (Alberto Soldati). A Aт, San Miguel de Tucumán, Argentina.

${ }^{51}$ Todavía en el año 1937 Barrere emitía comunicados oficiales recordando a los curas la prohibición de hacer política de partido. Barrere A. Comunicado oficial al clero diocesano. BODT, 28 de febrero de 1937, p. 517.

\section{()(1) $\$$}


bajo los parámetros del impulso romanizador de fines del siglo xIX y el modelo de Iglesia al que aspiraba, basada en el ideal de una institución centralizada y vertical, incidieron en su gestión al frente de la diócesis tucumana. Como se ha demostrado a lo largo del texto, los intentos de cimentar una sólida autoridad obispal estuvieron atravesados por innumerables tensiones.

Los mayores desafíos al proyecto del obispo emanaron de los curas párrocos de la diócesis, quienes representaron un contrapunto al modelo de Iglesia que prosperó en los años treinta. En líneas generales, las resistencias de los curas, sus muestras de autonomía y sus desacatos a las directivas obispales recibieron por parte de la jerarquía respuestas que oscilaron entre las advertencias y las sanciones eclesiásticas. No obstante, hubo casos en los que se desenvolvieron resistencias abiertas que derivaron en conflictos insalvables con el obispo, cuyos desenlaces fueron extremos, tal como fue analizado en las trayectorias de los curas Rodríguez Melero y Soldati.

Forjada en la experiencia al frente de las parroquias y en la atención de los templos y capillas, la práctica de los curas modeló una tradición propia de su función, basada en el contacto directo con las poblaciones locales y en una intervención social que no sólo se acotaba al trabajo "espiritual". Frente a esa realidad, Barrere proyectó un perfil de sacerdote obediente a la jerarquía, es decir, como un brazo ejecutor de la política obispal. Si bien los reconoció como agentes aptos para resolver problemas locales, sus decisiones y acciones debían supeditarse a la autoridad eclesiástica. Sin embargo, lejos de aventar las tradiciones de autonomía de los curas, algunas medidas impulsadas en esa dirección -especialmente las que promovieron la formación de un clero local-abrieron la posibilidad a la consolidación de un modelo de sacerdocio más consustanciado con los problemas locales y en estrecha vinculación con los actores de la comunidad. Es decir, un modelo de cura en el que las tradiciones sociales, culturales y familiares tuvieron un peso central.

En ese sentido, el análisis de las trayectorias de los curas párrocos de Trancas y Simoca nos permitió dimensionar los límites del proyecto obispal y las tensiones que caracterizaron la pugna por modelos de sacerdocio divergentes. Desde la perspectiva parroquial, las funciones pastorales de los curas resultaban mucho más complejas al encontrarse regidas bajo un criterio bifronte en el que, por un lado, como representantes de la Iglesia debían obediencia al obispo y, por otro, como pastores de su comunidad de fieles debían dar respuestas a las demandas locales. Tal como lo reflejan las historias de Rodríguez Melero y de Soldati, en el contacto con la vida cotidiana de las poblaciones imperaba la superposición de los problemas políticos y sociales

\section{()(1) $(3$}


con los bagajes culturales y familiares que portaban los curas. Dicha lógica se encontraba regida por criterios muy distintos a los que el nuevo obispo buscó imponer, basados en la disciplina y el sentido de "profesionalidad" de lo sagrado.

En suma, reparar en las experiencias de los curas párrocos y su relación con la autoridad jerárquica constituye una veta interesante por la cual explorar las marchas y contramarchas de los intentos centralizadores de la Iglesia católica. Llama a reflexionar no sólo en torno a los alcances y límites de las políticas institucionales sino también sobre las continuidades respecto a las tensiones que atravesaron la interrelación de los actores eclesiásticos.

\section{LISTA DE REFERENCIAS}

Aubert, R. et al. (1977). Nueva historia de la Iglesia (T. V). Madrid: Ediciones Cristiandad.

Ayrolo, V. (comp.). (2006). Estudios sobre clero iberoamericano, entre la independencia y el Estado-Nación. Salta: Eunsa.

Barral, M. E. (2007). De sotanas por la Pampa. Religión y sociedad en el Buenos Aires tardocolonial. Prometeo: Buenos Aires.

Bianchi, S. (1997). La conformación de la Iglesia católica como actor político-social: el episcopado argentino (1930-1960). En S. Bianchi y M. E. Spinelli (comps.), Actores, proyectos e ideas en la Argentina contemporánea (pp. 31-33). Tandil: Instituto de Estudios Históricos Sociales-Universidad Nacional del Centro.

Bianchi, S. (1998). La conformación de la Iglesia católica argentina (1930-1960). El clero diocesano. Trabajo presentado en las reuniones del grupo de trabajo Sociedad y Religión en la Argentina Contemporánea, Facultad de Filosofía y Letras, Universidad de Buenos Aires.

Bianchi, S. (2002). La conformación de la Iglesia católica como actor político-social. Los laicos en la institución eclesiástica: las organizaciones de elite 1930-1950. Anuario IEHS, 17, Tandil.

Bravo, M. C. (2008). Campesinos, azúcar y política: cañeros, acción corporativa y vida política en Tucumán (1895-1930). Rosario: Prohistoria.

Bravo, M. C. y Gutiérrez, F. (2009). La política azucarera argentina: de la concertación sectorial al tutelaje estatal (1928-1949). Ponencia presentada en las Segundas Jornadas de Historia de la Industria y los Servicios, Buenos Aires, Argentina.

\section{()(1) $(9$}


Di Stefano, R. (2008). La renovación de los estudios sobre el clero secular en la Argentina: de las reformas borbónicas a la Iglesia romana. Anuario, 7, 251-271. Centro de Estudios Históricos Carlos S. A. Segreti, Córdoba.

Di Stefano, R. y Zanatta, L. (2000). Historia de la Iglesia Argentina. Desde la conquista hasta fines del siglo Xx. Buenos Aires: Mondadori.

Gallardo, M. (2010). El clero secular inmigrante en la diócesis de Córdoba. Argentina, 1875-1925. METIS: Historia \& Cultura, 9(17), 97-115. Recuperado de http://www. ucs.br/etc/revistas/index.php/metis/article/view/1028

Ghio, J. M. (2007). La Iglesia católica en la política argentina. Buenos Aires: Prometeo.

Lida, M. (2006). Prensa católica y sociedad en la construcción de la Iglesia argentina en la segunda mitad del siglo xix. Anuario de Estudios Americanos, 63(1), 51-75. Recuperado de http://estudiosamericanos.revistas.csic.es/index.php/ estudiosamericanos/article/view/3/3

Lida, M. (2007). La Iglesia católica en las más recientes historiografías de México y Argentina. Religión, modernidad y secularización. Historia Mexicana. LVI(4), 1393-1426. Recuperado de http://historiamexicana.colmex.mx/index.php/RHM/ article/view/1640/1458

Lida, M. (2009). Los orígenes del catolicismo de masas en la Argentina, 1900-1934. Jahrbuch für Geschichte Lateinamerikas (Anuario de Historia de América Latina), 46, 345-370. Recuperado de https://www.degruyter.com/downloadpdf/j/ jbla.2009.46.issue-1/jbla.2009.46.1.345/jbla.2009.46.1.345.pdf

Lida, M. (2010). El catolicismo de masas en la década de 1930. Un debate historiográfico. En C. Folquer y S. Amenta (comps.), Sociedad, cristianismo y política. Tejiendo historias locales (pp. 395-424). Tucumán: UnSTA.

Lida, M. y Mauro, D. (2009). Catolicismo y sociedad de masas en Argentina: 1900-1950. Rosario: Prohistoria.

Mallimaci, F. (1988). El catolicismo integral en la Argentina (1930-1946). Buenos Aires: Biblos.

Mauro, D. (2009). La formación de la Acción Católica Argentina tras el ocaso del juego republicano. Ligas, círculos y comités católicos en la diócesis de Santa Fe, 1915-1935. Entrepasados, 36/37, 133-154.

Mauro, D. (2010). De los templos a las calles: catolicismo, sociedad y política. Santa Fe, 19001937. Santa Fe: Universidad Nacional del Litoral.

Obispado de Tucumán (1931). Segundo Sínodo Diocesano. Tucumán: Escuela Tipográfica del Colegio Salesiano Tulio García Fernández.

Santos Lepera, L. (2009). La Acción Católica tucumana: sociabilidad y cultura religiosa en los años treinta. El caso del Centro de Hombres de San Pablo. En M. Lida

\section{()ㅜ(1) $\$$}


y D. Mauro (coords.). Catolicismo y sociedad de masas. Argentina, 1900-1950 (pp. 141-160). Rosario: Prohistoria.

Santos Lepera, L. (2010). Asociacionismo y prácticas católicas en los años treinta: la Acción Católica tucumana y la configuración del laicado. En G. Vidal y J. Blanco (comps.), Estudios de la historia de Córdoba en el siglo xx (pp. 19-36). Córdoba: Ferreyra Editor.

Santos Lepera, L. (2012). Las parroquias de los pueblos azucareros de la diócesis de Tucumán durante los años treinta. En G. Caretta e I. Zacca (comps.), Derroteros en la construcción de religiosidades. Sujetos, instituciones y poder en Sudamérica, siglos XVII al xx (pp. 181-195). Salta: CePiHA/unsta/CONiCET.

Saranyana, J. (2002). Un siglo de teología latinoamericana. Prohistoria, VI(6), 225-252. Schatz, K. (1992). Historia de la Iglesia contemporánea. Barcelona: Herder.

Zanatta, L. (1996). Del Estado liberal a la nación católica. Iglesia y ejército en los orígenes del peronismo. 1930-1943. Buenos Aires: Universidad Nacional de Quilmes.

\section{OTRAS FUENTES}

AAT Archivo del Arzobispado de Tucumán. 